\section{Blocking the acquisition of control by an auditory stimulus with pretraining on brightness ${ }^{1}$}

C. G. MIIES, Alcoholism and Drug Addiction Rescarch Foundation. Toronto 4. Canada

One group of pigeons, Group TLI-L.2. were rewarded for pecking a lighted response key in the presence of a tone and were not rewarded for pecking a less bright response key' in the prescince of noise. A second group of pigeons. Group (L.1-L.2)(TL1-L.2), were similarly treated after first being gil'en extensive pretraining with noise and the brighter light on positive trials and noise and the duller light on negative trials. Tests for stimulus control revealed strong control by tone in Group TI.1-L.2 and very little control by tone in Group (l, l-1.2)(TI.1-1.2). Control bl. brighthess in Group TI.1-L.2 was less than in Group (1.1-1.2)(TI.1-1.2).

Discrimination training on one stimulus dimension may drastically reduce the amount of control atcquired by a subsequently added second dimension. A CER procedure was used by Kamin (1968) to demonstrate this effect in classical conditioning. In one group, Kamin showed that rats will suppress barpressing behavior in the presence of noise that has been paired with shock. In a second group, the same training was given but, instead of testing, training was continued with light added to noise, so that both stimuli in compound signaled shock. Tests with light alone gave no suppression. However, when light and noise were presented in a compound to another group of Ss from the outset of training, tests with light alone indicated almost total suppression. Thus. prior training with noise was said to "block" the acquisition of aversive control by light. A similar effect has been reported by Lawrence (1950), who trained rats on a successive-discrimination task with one cue relevant and a second cue irrelevant. In the second phase of the experiment, both cues were made relevant for the solution of a choice-discrimination problem. Opposed-cue and relearning tests were then administered, the results of which

Fig. 1. Mean responses per $S-$ trial for each session of light-only training and each session of compound-stimulus training for Group ( L 1 - L 2 ) ( T L 1-L 2) and Group (TL1-L2). indicated that the dimension relevant during initial training was preferred. Lawrence (1950) argued that through prior training the cue had "acquired distinctiveness." Another body of theory and experimentation has tended to favor explanations of the phenomenon in terms of "selective attention" (Mackintosh, 1965). The experiment to be reported was not designed to distinguish between these various accounts but primarily to explore the generality of the effect.

SUBJECTS AND APPARATUS

The Ss were 5- to 6-year-old male White King pigeons that were run at approximately $80 \%$ of their free-feeding weight. The basic apparatus was three st andard Le high Valley operant-conditioning chambers, equipped with response keys that could be backlighted. The experiment was controlled by five-channel tape readers, relay switching circuits, and timers. Total counts of various events were recorded on impulse counters.

Auditory stimuli were either a tone at 1,000 cycles or a broad-band white noise. When tone was switched on, noise was switched off. When tone was not present on trials, noise was on throughout the experimental sessions. The intensity of both tone and noise were maintained at $80 \mathrm{~dB}$ sound pressure. Visual stimuli were different brightness levels of the key, which were obtained by varying the voltage across the stimulus lamp. These were designated L1 (24.3V), L2 (21.9V), L4 (19.1V), and L5 (16.3V).

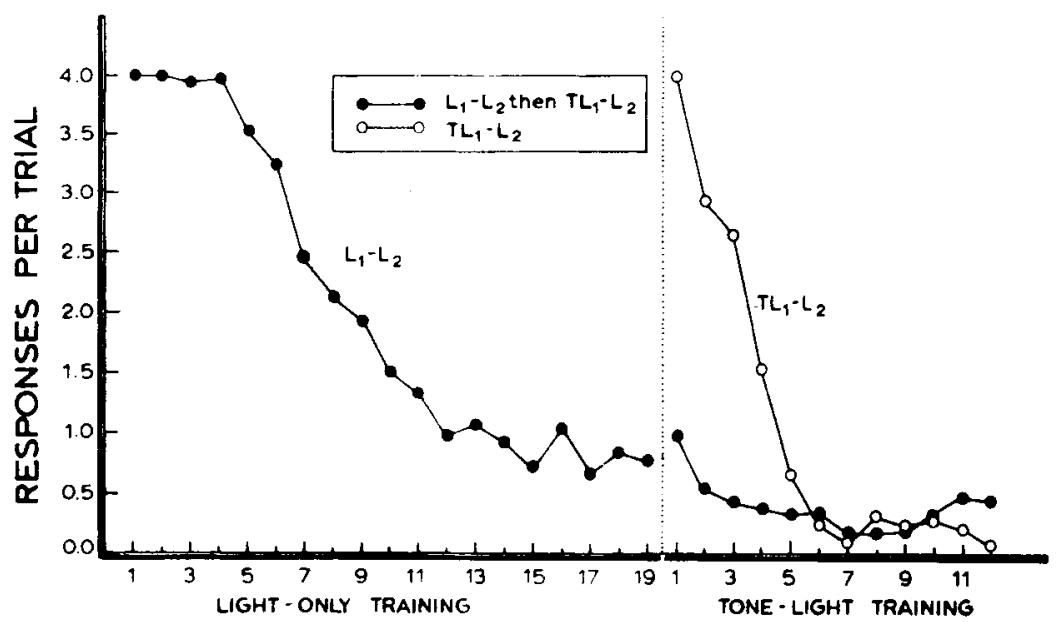

SESSIONS
The Ss were initially shaped to peck a lighted key (L1). For six Ss the tone was present, and for a further six it was absent. All Ss were then given four sessions of pretraining with the stimuli which had been present in shaping. Each session consisted of 40 trials separated by intertrial intervals ranging from 35 to $90 \mathrm{sec}$, during which a dark key and white noise were present. Throughout all experimental sessions, the houselight was on. Trials began with the onset of the stimuli presented in pretraining, i.e., light for half the Ss and tone plus light for the rest. If the response requirement was completed (this was raised from one to four during the first five trials of the first session of pretraining), the trial was terminated with 4-sec access to grain. Otherwise the trial ended, without reinforcement, after $8 \mathrm{sec}$. During the discrimination-training sessions that followed, both positive and negative trials were presented. Forty reinforced or $\mathrm{S}+$ trials were randomly intermixed with 40 nonreinforced or $S$ - trials.

The Ss pretrained with L1 positive were designated as Group (L1-L2)(TL1-L2). For this group, discrimination training consisted of 19 sessions where L1 was the stimulus on positive trials and L2 constituted the stimulus on negative trials. A further 12 sessions of discrimination training were given in which the tone was added to $\mathrm{L} 1$ on positive trials. The $\mathrm{Ss}$ pretrained with tone and L1 (TL1) were given 12 sessions of discrimination training with TL1 on positive and L2 on negative trials. This group was designated as Group TL1-L?

Tests for stimulus control were given after discrimination training. Four test sessions were run on successive days. Tests were made at four points along a generalization gradient based on decreasing intensities of the keylight; the four light 
levels L1, L2, L4, and L5 were presented. At each light level, trials were presented with and without tone, yielding a total of eight different stimuli. The order of presentation was varied in 10 independent random orders, making a total of 80 trials per test session. Except for the absence of reinforcement, trials were programmed and terminated as in training. From these data, it was possible to assess the slope of the generalization gradient over light levels and an overall index of control by tone could be calculated. This index, designated $R$, consists of the ratio of the number of responses on tone trials to the total number of responses.

\section{RESULTS}

Pretraining and Training

The mean probability of completing the response requirement to positive trials was almost 1.00 throughout pretraining and training. Intertrial responding was very infrequent. Figure 1 shows the mean number of $S-$ responses per trial for Group (L1-L2)(TL1-L2) for each of the 19 sessions of training on $\mathrm{L} 1$ vs $\mathrm{L} 2$ and for each of the subsequent sessions of training with TL1 vs L2. Mean S- responses per trial for the 12 sessions of discrimination training with TL1 vs L2 for Group TL1-L2 are also presented. In the 19 th session of training, the mean number of responses per trial for Group (L1-L2)(TL1-L2) was .77. Over the next 12 sessions of training, the mean was .40 , which can be compared to a mean of 1.11 over a similar 12 sessions of training for Group TL1-L2. Thus, it is quite clear that prior training with $\mathrm{L} 1$ vs L2 considerably reduced the amount of responding to $S-$. It is also evident from an examination of Fig. 1 that the presence of the tone from the outset of training substantially aided the formation of the discrimination. The rate at which $\mathrm{S}+$ was discriminated from $S-$ was very much slower in Group (L1-L2)(TL1-L2) than in Group TL1-L2.

Fig. 2. Mean responses to tone and no-tone test trials relative to responses to TL1 at each of four light levels for Group (L 1 - L 2) ( T L 1-L 2) and Group (TL1-L2).
Test for Stimulus Control

In Fig. 2,2 the mean number of responses to each test stimulus is presented as proportions of responding to TL1. The mean value of the $R$ index (proportion of total responding in the presence of tone on test) for Group (L1-L2)(TL1-L2) was .55, which is significantly lower than a value of .89 for Group TL1-L2 $(\mathrm{t}=4.94, \mathrm{df}=10$, $p<.01)$. It is also apparent that the gradient over light levels is sharper in Group (L1-L2)(TL1-L2).

\section{DISCUSSION}

The relatively small degree of control by tone on the test for Group (L1-L2). (TL1-L2) can be attributed to pretraining on light-level differences. An interpretation of this result, suggested by Lawrence (1950), emphasizes that the pretraining may produce a reordering of association values. The steeper gradient over light levels for Group (L1-L2)(TL1-L2) is quite compatible with this view. However, the accompanying absolute reduction in control by tone suggests that more than simply a reordering of association values has taken place. Explanations of the data in terms of blocking or attention are equally tenable. One view of blocking, in this case, suggests that prior training with L1 vs L2 precluded the development of an association between the tone and the response. Insofar as the results are an

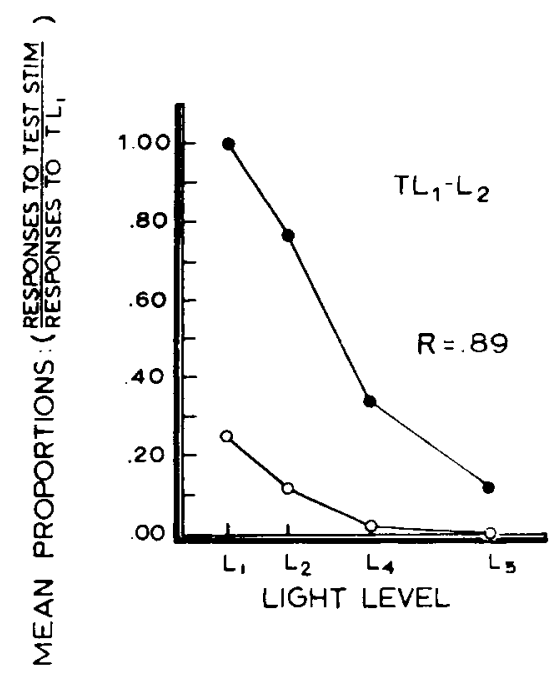

example of control between two features being inversely related, they are compatible with attention theory. It should be noted. however, that this conclusion relies entirely on a between-groups comparison.

\section{REFERENCES}

KAMIN, L. J. "Attention-like" processes in classical conditioning. In M. R. Jones ( $\mathrm{l}$ d.). Miami symposium on the prediction of behavior. Coral Gables, Fla: University of Miami Press, 1968. Pp. 9-31.

LAWRENCE, D. H. Acquired distinctiveness of cues. II. Selective association in a constant stimulus situation. Journal of Experimental Psychology, 1950, 40,175-188.

MACKINTOSH, N. J. Selective attention in animal discrimination learning. Psychological Bulletin, 1965, 64, 124-150.

MILES, C. G. Acquisition of control by the features of a compound stimulus in discriminative operant conditioning. Unpublished doctoral dissertation. McMaster University, 1965.

\section{NOTES}

1. From a dissertation (Miles, 1965) submitted in partial fulfillment of the requirements for the PhD degree, McMaster University, 1965. The author wishes to record his appreciation of the encouragement and help given by his supervisor, H. If. Jenkins. NRC Grants to H. M. Jenkins supported this research.

2. The spacing of the light levels in this figure was achieved by a fractionation procedure using human Ss. The spacing is used simply as an aid in visualizing the results and plays no part in their interpretation.

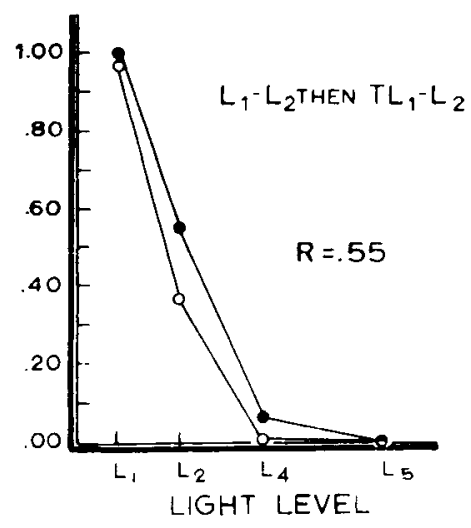

